\title{
The Fate of Mesoinositol during the Growth of an Inositol-dependent Yeast Kloeckera brevis
}

\author{
By R. M. C. DAWSON, R. W. WHITE AND N. FREINKEL \\ Biochemistry Department, Agricultural Research Council Institute of Animal Physio- \\ logy, Babraham, Cambridge, England, and Thorndike Memorial Laboratory, Second \\ and Fourth Medical Services (Harvard), Boston City Hospital, Mass., U.S.A.
}

(Received 7 July 1961)

\section{SUMMARY}

An inositol-dependent yeast Kloeckera brevis was grown in a medium limited in inositol and the fate of the inositol determined. All of the inositol was taken in by the yeast and combined in an organic form. Fractionation of the yeast after disruption in a Hughes press showed that $31-38 \%$ of the combined inositol was soluble in trichloroacetic acid solution and 43-65 \% was soluble in neutral or acidified lipid solvents. The trichloroacetic acid extract contained three inositol components; one minor one was identified as inositol monophosphate. The major component was a neutral derivative of mesoinositol which was not identified as any known naturally-occurring form of combined inositol. The lipid extracted with neutral solvents contained an inositide whose properties were those of phosphatidyl inositol. The lipid inositol extracted with acidified solvents appeared to be present in a lipoprotein.

\section{INTRODUCTION}

It is now well established that many yeasts require inositol as an essential growth factor. So far attempts to demonstrate a metabolic lesion in such organisms caused by a lack of inositol have not been successful. It seemed likely therefore that a lead on the biochemical role of inositol in yeast growth might be provided by a study of the chemical fate of the inositol during growth. Yarbrough \& Clark (1957) found that most of the inositol in Schizosaccharomyces pombe could be extracted with lipid solvents, e.g. chloroform + methanol mixtures, while Smith (1951) reported that with Saccharomyces carlsbergensis much was bound as a 'phytin-like' compound. Ridgway \& Douglas (1958) showed that in $S$. carlsbergensis most of the combined inositol was present in the cytoplasmic particles rather than in the cell wall: about $40 \%$ was soluble in lipid solvents and the remainder was not extracted with trichloroacetic acid solution.

In the present work Kloeckera brevis was used as the test organism. It has an absolute and highly specific dependence on mesoinositol for its growth (Campling \& Nixon, 1954; Hartree, 1957). The fate of inositol in the growth medium was determined not only by direct analysis of the yeast fractions, but also by using ${ }^{3} \mathrm{H}$ labelled inositol as a marker. 


\section{METHODS}

Growth of Kloeckera brevis. A stock culture of Kloeckera brevis (NCYC 328) was maintained on agar slopes. The yeast was grown at $25^{\circ}$ for 3 days in $250 \mathrm{ml}$. of the medium described by Campling \& Nixon (1954) contained in large Erlenmeyer flasks. The cultures were shaken once daily. Meso-inositol was added to a concentration of $1 \mu \mathrm{g} . / \mathrm{ml}$.

Fractionation of yeast. The yeast was harvested by centrifuging (1000 $\mathrm{g}$ av. for $20 \mathrm{~min}$.) and washed twice with water (1/5th volume of original culture); this resulted in a negligible loss of soluble inositol. The yeast was then either fractionated directly or after disruption in a Hughes (1951) press, with two pressings either at $-20^{\circ}$ or $-78^{\circ}$. A flow sheet of the fractionation is shown in Fig. 1. The yeast recovered from $1 \mathrm{l}$. of medium was extracted twice with $15 \mathrm{ml}$. warm $\mathrm{CHCl}_{3}+$ $\mathrm{CH}_{3} \mathrm{OH}(1+\mathrm{I} ; \mathrm{v} / \mathrm{v})$ for $10 \mathrm{~min}$. and then once with $15 \mathrm{ml}$. of warm $\mathrm{CHCl}_{3}+\mathrm{CH}_{3} \mathrm{OH}$ $(1+2 ; \mathrm{v} / \mathrm{v})$. The supernatant fluids obtained by centrifuging were mixed and $\mathrm{CHCl}_{3}$ added until the final solvent composition was $\mathrm{CHCl}_{3}+\mathrm{CH}_{3} \mathrm{OH}(2+1 ; \mathrm{v} / \mathrm{v})$. The lipid extract was then washed with 0.2 volumes of either $0.9 \%(\mathrm{w} / \mathrm{v}) \mathrm{NaCl}$ or water to remove water-soluble non-lipid impurities according to Folch, Lees \& SloaneStanley (1957). The washings, which contained some water-soluble combined inositol, were saved for adding to the trichloroacetic acid extract of the yeast.

The solvent-extracted yeast residue was then extracted twice with $15 \mathrm{ml}$. of $5 \%(\mathrm{w} / \mathrm{v})$ trichloroacetic acid solution for $5 \mathrm{~min}$. at $4^{\circ}$. The extracts were combined with the washings from the lipid purification and the mixture then washed three times with equal volumes of ether to remove trichloroacetic acid. The aqueous layer was filtered to yield a clear water-soluble fraction.

The solvent and trichloroacetic acid extracted yeast residue was then extracted twice with $15 \mathrm{ml}$. $\mathrm{CHCL}_{3}+\mathrm{CH}_{3} \mathrm{OH}(2+1 ; \mathrm{v} / \mathrm{v})$ containing $0 \cdot 33 \mathrm{ml}$. concentrated $\mathrm{HCl} / 100 \mathrm{ml}$, with the intention of extracting protein-bound lipid-inositol (see Lebaron \& Folch, 1956).

Inositol assay. Inositol was assayed by the procedure of Campling \& Nixon (1954) with Kloeckera brevis as the test organism. Combined inositol was hydrolysed for $18 \mathrm{hr}$. at $105^{\circ}$ in $5 \mathrm{~N}-\mathrm{HCl}$, the acid removed in vacuo, the residue made up to a known volume with water and adjusted to $\mathrm{pH} 5$ with $\mathrm{NaOH}$ before assay.

Radioactivity experiments. Inositol randomly-labelled with tritium $\left({ }^{3} \mathrm{H}\right)$ was obtained from Tracerlab Inc., Waltham, Mass., U.S.A., and had been prepared by the Wilzbach (1957) method. It was purified by two crystallizations from ethanol+ water and the radioactivity was chromatographically homogeneous when tested on paper in several solvent systems. The activity was $7 \cdot 8 \mu \mathrm{C} / \mu$ mole. ${ }^{3} \mathrm{H}$ was assayed in a Nuclear Chicago (Chicago, U.S.A.) flow counter. Paper chromatograms were cut into $1 \mathrm{~cm}$. wide strips before assay.

${ }^{32} \mathrm{P}$-labelled yeast was prepared by growing Kloeckera brevis in Campling \& Nixon's (1954) growth medium in which the concentration of $\mathrm{KH}_{2} \mathrm{PO}_{4}$ had been decreased to $0 \cdot 3 \mathrm{~g}$. $/ \mathrm{l}$. and $\mathrm{H}_{3}{ }^{32} \mathrm{PO}_{4}$ added at an activity of $2 \mu \mathrm{C} / \mathrm{ml}$.

Paper chromatography and ionophoresis. Whatman No. 1 paper was used after washing with $2 \mathrm{~N}$-acetic acid. Descending chromatography was carried out with the following solvents: $(a)$ isopropanol + acetic acid + water $(3+1+1 ; \mathrm{v} / \mathrm{v}) ;(b)$ ethyl acetate + propanol + water $(13+24+7 ; \mathrm{v} / \mathrm{v})$, and ascending with ethanol $+27 \%$ 
$(\mathrm{w} / \mathrm{v}) \mathrm{NH}_{3}$ solution $(3+2 ; \mathrm{v} / \mathrm{v})$. High voltage $(50 \mathrm{~V} / \mathrm{cm}$.) ionophoresis was carried out under toluene in an apparatus similar to that described by Ryle, Sanger, Smith \& Kitai (1955) with a volatile pyridine + acetic acid buffer $(\mathrm{pH} \mathrm{3 \cdot 6)}$. For preparative paper-electrophoresis or ionophoresis the fractions were run as strips; after location of the separated bands they were eluted by descending chromatography with water as solvent.

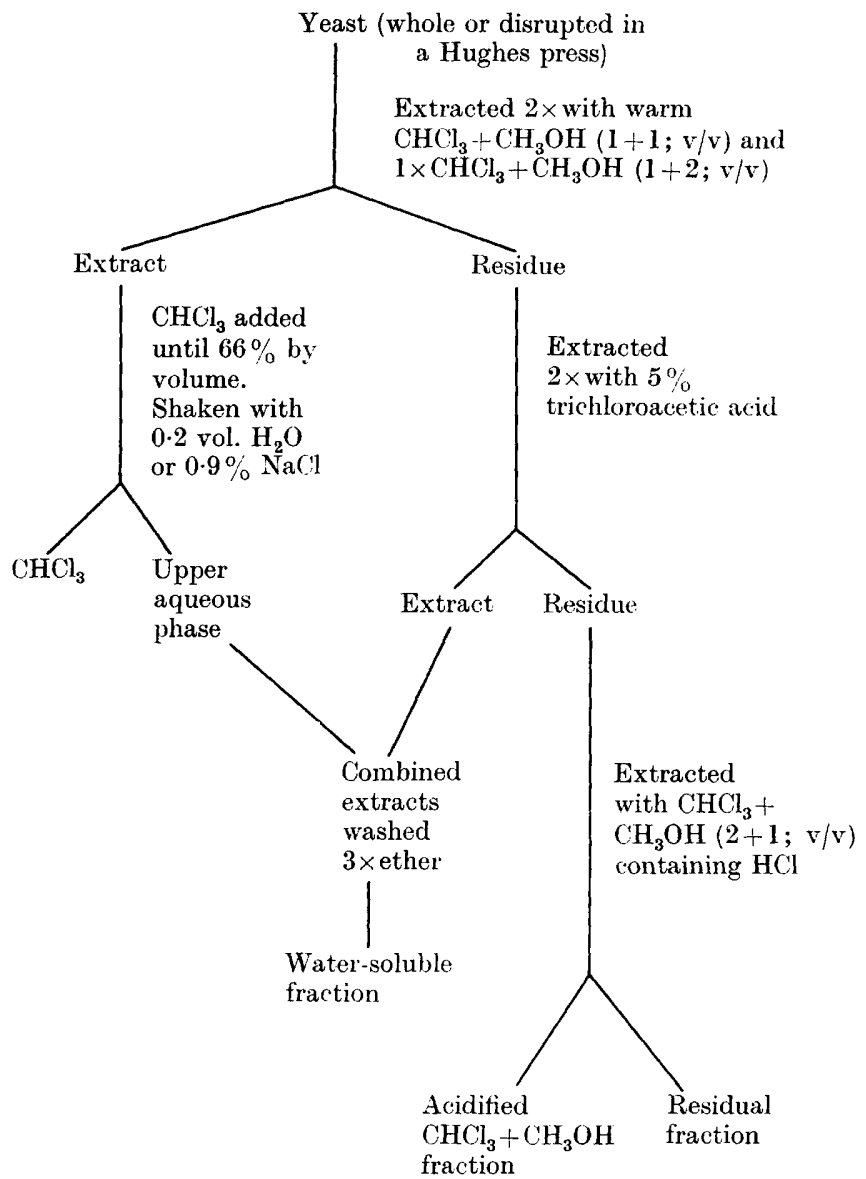

Fig. 1. Flow sheet of the fractionation of $K$. brevis cells.

Polyols were detected on paper by using the acetone $+\mathrm{AgNO}_{3}$ and ethanolic $\mathrm{NaOH}$ reagents of Trevelyan, Procter \& Harrison (1950); phosphate esters were detected with the acid molybdate reagent of Hanes \& Isherwood (1949) followed by ultraviolet irradiation.

Materials. Inositol monophosphate was obtained from the California Foundation for Biochemical Research (Los Angeles, U.S.A.) and sodium phytate from L. Light and Co. Ltd. (Colnbrook, Buckinghamshire, England). Inositol diphosphate, inositol triphosphate and glycerylphosphorylinositol were prepared (Dawson \& Dittmer, 1960) and phosphatidyl inositol (monophosphoinositide) was isolated from liver (Dawson, 1958). Bornesitol (1:0-methyl mesoinositol) was kindly given by Professor S. J. Angyal (Sydney). 


\section{RESULTS}

\section{Recovery of inositol from yeast}

Table 1 shows the percentage distribution of the inositol recovered from Kloeckera brevis after its fractionation into water soluble, lipid and residual fractions. In two of the experiments the total recovery of inositol was measured and amounted to 95 and $99 \%$ of that added to the growth medium; no detectable inositol remained in the medium. Although the percentage distribution of the inositol recovered showed appreciable variation in different cultures, it is clear that only a minor percentage of the combined inositol was extracted from whole yeast cells with trichloroacetic acid and lipid solvents, leaving the major portion in the insoluble residue.

Table 1. Percentage distribution of inositol in fractions from Kloeckera brevis

Results as \% of total inositol recovered

Trichloroacetic acid extract Chloroform + methanol extract Acidified chloroform + methanol extract Insoluble residue

\begin{tabular}{rrrrrr}
\multicolumn{3}{c}{} & \multicolumn{4}{c}{$\begin{array}{c}\text { Yeast disrupted twice } \\
\text { in Hughes press }\end{array}$} \\
$\mathbf{8}$ & $\mathbf{7}$ & 14 & $\mathbf{3 2}$ & 31 & 38 \\
7 & 16 & 3 & 23 & 14 & 34 \\
20 & 20 & 4 & 20 & 51 & 15 \\
65 & 57 & 79 & 25 & 4 & 13
\end{tabular}

The yeast cells proved to be particularly difficult to disrupt as judged by their microscopic appearance after Gram staining. Boiling with solvents or water, freezing and thawing or shaking in a Mickle shaker proved only partially effective. Treatment in a MSE Mullard Ultrasonic disintegrator with a 60 watt power output was ineffective, but partial breakage (80\%) was obtained after 50 min. in a Mullard instrument with a $\mathbf{5 0 0}$ watt output (the latter kindly performed by Dr R. Davies, Microbiological Unit, Department of Biochemistry, University of Cambridge). Crushing in a Hughes (1951) press proved to be reasonably effective and two treatments led to $70-90 \%$ breakage of the yeast cells.

When yeast cells which had been partially disrupted on a Hughes press were fractionated the distribution picture of inositol changed considerably: the watersoluble fraction changed from 7-14\% of the total inositol to 31-38 \%, and there was an appreciable decrease in the percentage of residual inositol (from 57-79\% to 4-25\%). In addition, the total lipid-inositol extracted with neutral and acidified chloroform + methanol showed some increase from 7-36\% to $43-65 \%$.

Composition of the water-soluble inositol fraction. This fraction was investigated by using ${ }^{3} \mathrm{H}$-inositol labelled yeast which had been disrupted in a Hughes press. Chromatography and ionophoresis of aqueous extracts showed that the fraction was multiple, consisting of one major and two minor radioactive components. None of the components was sedimented on centrifuging at 78,000-173,000 $\mathrm{g}$ for $30 \mathrm{~min}$. On ionophoresis at $\mathrm{pH} 3 \cdot 6$, the major ${ }^{3} \mathrm{H}$ component did not move, while both the minor components moved towards the anode, the fastest having a mobility identical with that of an internal inositol monophosphate marker (Fig. 2). This minor component contained phosphorus and its identification was confirmed by finding an exact coincidence of the radioactive peak with that of an added inositol monophosphate marker on paper chromatography in methanol + formic acid + water 
$(80+13+7 ; \mathrm{v} / \mathrm{v})$ solvent, $R_{F} 0 \cdot 45$. The amounts and proportions of the second minor spot varied from preparation to preparation. Its ionophoretic mobility at pH 3.6 was similar to that of glycerylphosphorylinositol but it could be readily separated from this compound on paper chromatography with an ethanol $+\mathrm{NH}_{3}$ solvent.

The separated neutral major ${ }^{3} \mathrm{H}$-component was distinguished from free inositol by paper chromatography in both the propanol + ethyl acetate + water and isopropanol + acetic acid + water solvents, when it ran in both systems more slowly than the free hexitol (Fig. 3). Very small amounts of free ${ }^{3} \mathrm{H}$-inositol were occasionally seen in these chromatograms as well as the unknown component (Fig. 3). This

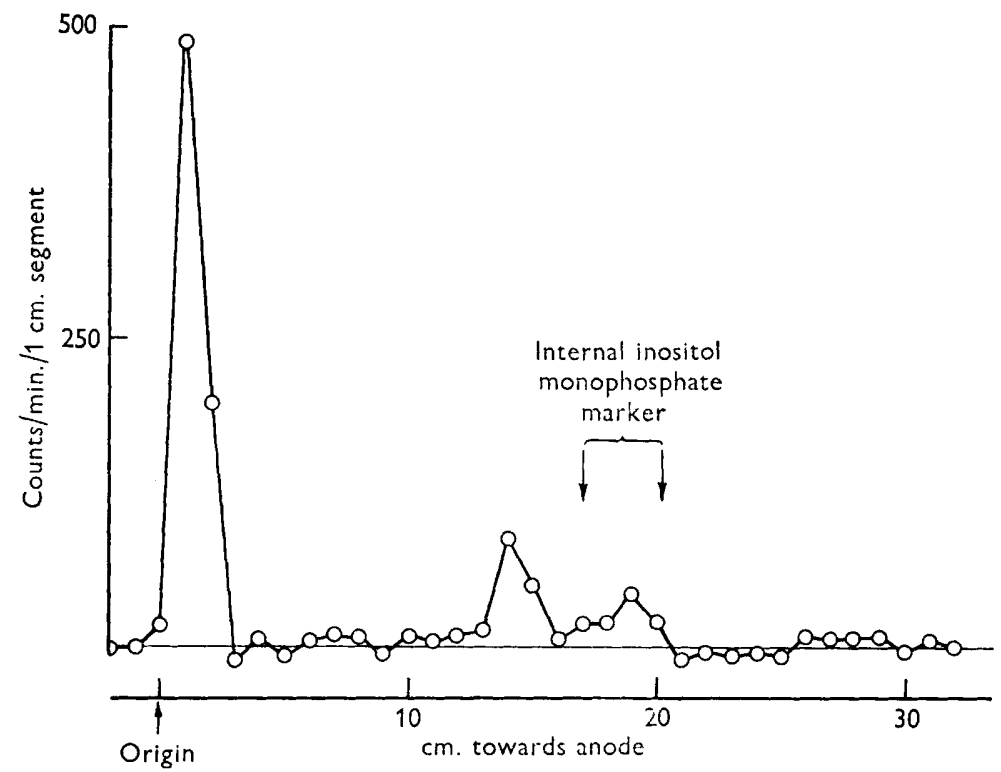

Fig. 2. Separation of water-soluble ${ }^{3} \mathrm{H}$-labelled inositol derivatives from yeast. Ionophoresis at $\mathrm{pH} 3.6$ for $100 \mathrm{~min}$. at 50 volts $/ \mathrm{cm}$. The internal inositol monophosphate marker was revealed by spraying to detect phosphorus.

latter compound was not capable of supporting the growth of Kloeckera brevis when added to a growth medium under standard assay conditions. However, it did so after a fairly vigorous acid hydrolysis, e.g. $6 \mathrm{hr}$. in $2 \mathrm{~N}-\mathrm{HCl}$ at $105^{\circ}$. This suggests that free mesoinositol was liberated, since the growth of the organism was specifically dependent on the presence of this substance in the growth medium. This was confirmed by acid hydrolysis of the compound, followed by paper chromatography of the hydrolysate in propanol + ethyl acetate + water. A ${ }^{3} \mathrm{H}$-labelled compound was formed which reacted with alkaline silver nitrate (Trevelyan et al. 1950) and whose radioactivity migrated exactly to the same position as that of an internal inositol marker. There was no evidence of the formation on acid hydrolysis of other alkaline silver-reducing polyols, such as glucose or mannose.

The unknown component was readily separated on ionophoresis from the following phosphorylated derivatives : inositol monophosphate, inositol diphosphate, inositol triphosphate, glycerylphosphorylinositol, phytic acid. No phosphate was 
detected on spraying chromatograms nor were ninhydrin-reacting groups apparent. This is consistent with its failure to move on ionophoresis, and its ability to pass through a monobed resin (Amberlite MB 1). The compound was chromatographically distinguished from another series of naturally occurring inositol derivatives, the monomethylethers. Thus, in isopropanol + acetic acid + water and in propanol + ethyl acetate + water, it ran more slowly than free inositol and much more slowly than bornesitol (1:0-methyl mesoinositol; Fig. 3). In general all the monomethyl ethers of inositol appear to run faster than free inositol in solvents of this type (Posternak, Reymond \& Haerdi, 1955; Angyal, McHugh \& Gilham, 1957).

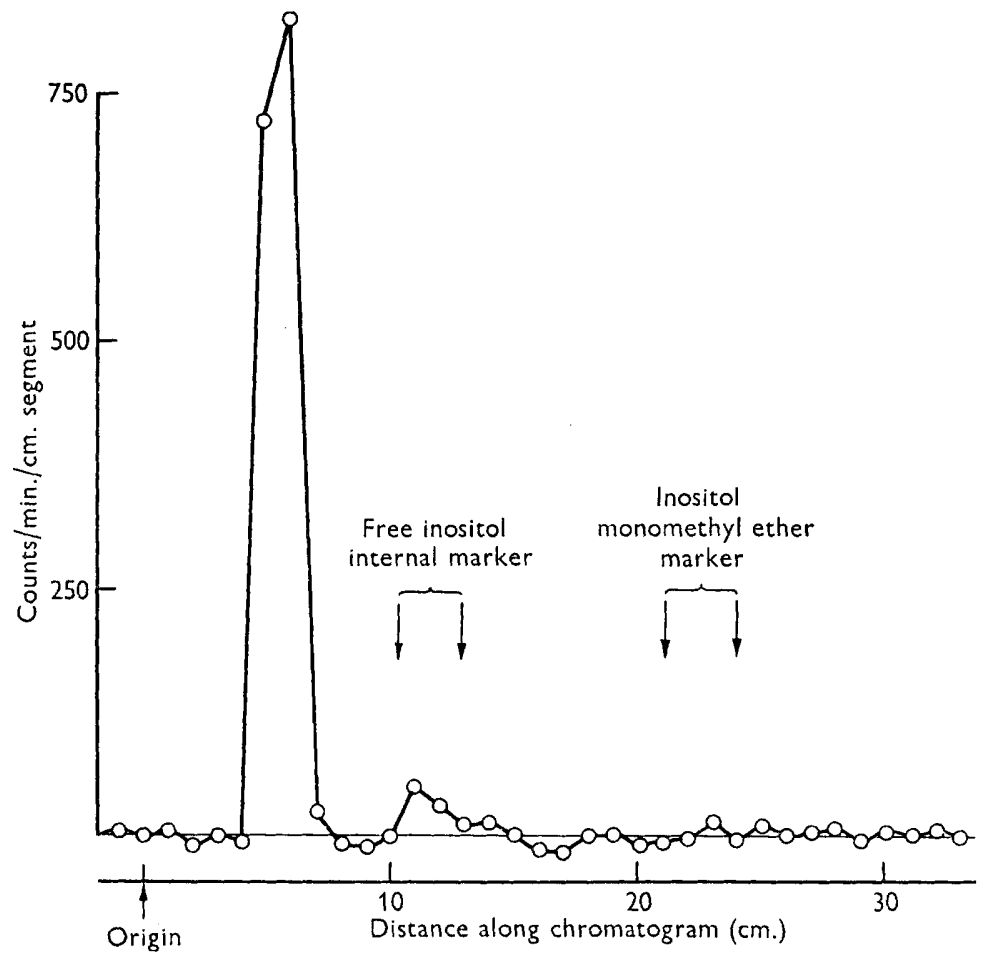

Fig. 3. Separation of major water-soluble ${ }^{3} \mathbf{H}$-labelled inositol derivative from free inositol and inositol monomethyl ether. Solvent $n$-propanol + ethyl acetate $+\mathrm{H}_{2} \mathrm{O}$; $48 \mathrm{hr}$. descending paper chromatography. Markers were detected by spraying to reveal polyols.

Examination of the lipid fractions. When the lipids extracted both with neutral solvents and acidified solvents from ${ }^{32} \mathrm{P}$-labelled yeast were hydrolysed for $10 \mathrm{~min}$. with $5 \mathrm{~N}-\mathrm{HCl}$ at $100^{\circ}$, ionophoresis of the hydrolysis products at $\mathrm{pH} 3.6$ separated a small radioactive spot with a mobility identical with that of inositol monophosphate. A large amount of glycerophosphate was also produced. After de-acylation by mild alkaline hydrolysis followed by chromatography and ionophoresis (Dawson, 1960), the material extracted with neutral lipid solvents gave spots on radioautography which were in the typical position of glycerylphosphorylinositol and inositol monophosphate. These are alkaline degradation products of phosphatidyl inositol (Dawson, 1960). The same general picture was observed after labelling the 
yeast with ${ }^{3} \mathrm{H}$-inositol. However, after alkaline treatment of the ${ }^{32} \mathrm{P}$-labelled material extracted with acidified lipid solvents no glycerylphosphorylinositol or phösphoryl inositol was detected on chromatography and ionophoresis, followed by radioautography. When an acidified chloroform + methanol solution of the lipid from ${ }^{3} \mathrm{H}$-labelled yeast was shaken with $\mathbf{0 . 2}$ vol. of water, the ${ }^{3} \mathrm{H}$ became concentrated at the interface on centrifugation. This is the behaviour to be expected if the ${ }^{3} \mathrm{H}$-inositol were present as in a lipoprotein (Lebaron \& Folch, 1956). In the neutral lipid extract, large amounts of lecithin and phosphatidyl ethanolamine were detected with smaller amounts of phosphatidyl serine and a polyglycerolphospholipid of a cardiolipid type. These were not present in the material extracted with acidified solvents.

Since mannose-containing phosphoinositides have been described in bacteria (Vilkas \& Lederer, 1956; Nojima, 1959), samples of the two lipid fractions were hydrolysed for $48 \mathrm{hr}$. in $5 \mathrm{~N}-\mathrm{HCl}$ at $105^{\circ}$ and the hydrolysate tested chromatographically for mannose. Neither mannose nor glucose was detected on spraying for polyols, although inositol and glycerol were clearly revealed.

\section{DISCUSSION}

The present results show that Kloeckera brevis only yielded a large part of its combined inositol to extracting solvents when it has been previously disrupted by mechanical shearing in a Hughes press. This mechanical shearing was associated with a microscopically visible disruption of the yeast cell and a disappearance of Grampositive staining. Many other treatments of the yeast did not give satisfactory disruption and the barrier to effective inositol extraction remained. As the two treatments in the Hughes press only gave a degree of breakage which was visually estimated at between $\mathbf{7 0}$ and $90 \%$, it would seem reasonable to suppose that completely disrupted cells would yield practically all their combined inositol to trichloroacetic acid and lipid solvents.

Of the water-soluble inositol extracted from the yeast, a major portion consisted of a neutral derivative of inositol which yielded mesoinositol on acid hydrolysis. This could not be equated with any known naturally-occurring water-soluble form of combined inositol, e.g. phytic acid. The yeast cannot use this water-soluble combined inositol to support growth, which suggests either a permeability barrier or the lack of a suitable enzyme for converting the compound to free mesoinositol.

It is possible that the minor component in the water-soluble fraction, inositol monophosphate, is a breakdown product of the phosphatidyl inositol present in the yeast. In mammalian tissues inositol monophosphate is not on the biosynthetic pathway of phosphatidyl inositol (Agranoff, Bradley \& Brady, 1958; Paulas \& Kennedy, 1960); but recently enzymes have been described which produce it by hydrolysis of this lipid (Dawson, 1959; Kemp, Hübscher \& Hawthorne, 1959).

Although the de-acylation products of the inositide present in the yeast were chromatographically identical with those of phosphatidyl inositol, a positive identification must await the isolation of the lipid itself. Phosphatidyl inositol has been isolated from the non-inositol-dependent yeast Saccharomyces cerevisiae (Hanahan \& Olley, 1958) and phosphatidyl-inositomannosides from Mycobacterium tuberculosis (Vilkas \& Lederer, 1956; see also Nojima, 1959). The latter compounds, 
however, would yield mannose on acid hydrolysis and this sugar was absent from the present lipid extracts.

The growth of Kloeckera brevis presumably ceases in inositol deficiency because the cells are not able to synthesize one or other of the inositol-containing components which are essential for budding and development of daughter cells. From the properties of these components and their tight attachment to the yeast cell, it seems more probable that they are essential structural elements rather than coenzymes in some metabolic process essential to yeast growth. This is supported by studies with the inositol-dependent yeast Saccharomyces carlsbergensis where inositol deficiency caused the formation of abnormal cell walls with the failure of daughter cells to separate, leading to large cellular aggregates (Smith, 1951; Ghosh, Charalampous, Sison \& Borer, 1960). At the same time no change in the intermediary metabolism could be detected.

This investigation was supported in part by Research Grant A-1571 and Training Grant 2A-5060, National Institute of Arthritis and Metabolic Diseases, United States Health Service, Bethesda, Md., U.S.A. and by the Capps Fund of Harvard University, and the Wellcome Trust, London. One of us (N.F.) is an investigator of the Howard Hughes Medical Institute.

\section{REFERENCES}

Agranoff, B. W., Bradley, R. M. \& Brady, R. O. (1958). The enzymatic synthesis of inositol phosphatide. J. biol. Chem. 233, 1077.

Angyal, S. J., McHugh, D. J. \& Gilham, P. T. (1957). The paper chromatography of cyclitols. J. Chem. Soc. p. 1432.

Campling, J. D. \& Nixon, D. A. (1954). The inositol content of foetal blood and foetal fluids. J. Physiol. 126, 71.

Dawson, R. M. C. (1958). Studies on the hydrolysis of lecithin by a Penicillum notatum phospholipase B preparation. Biochem. J. 70, 559.

Dawson, R. M. C. (1959). Studies on the enzymic hydrolysis of monophosphoinositide by phospholipase preparations from $P$. notatum and ox pancreas. Biochim. biophys. Acta, 33, 68.

Dawson, R. M. C. (1960). A hydrolytic procedure for the identification and estimation of individual phospholipids in biological samples. Biochem. J. 75, 45.

Dawson, R. M. C. \& DitTmer, J. C. (1960). The hydrolysis products of triphosphoinositide B prepared from ox brain. Biochem. J. 76. $42 \mathrm{P}$.

Folch, J., Lees, M. \& Sloane-Stanley, G. H. (1957). A simple method for the isolation and purification of total lipids from animal tissues. J. biol. Chem. 226, 497.

Ghosh, A., Charalampous, F., Sison, Y. \& Borer, R. (1960). Metabolic functions of myo-inositol. I. Cytological and chemical alterations in yeast resulting from inositol deficiency. J. biol. Chem. 235, 2522.

Hanahan, D. J. \& Olley, J. N. (1958). Chemical nature of monophosphoinositides. J. biol. Chem. 231, 813.

Hanes, C. S. \& Isherwood, F. A. (1949). Separation of the phosphoric esters on the filter paper chromatogram. Nature, Lond. 164, $110 \%$.

Hartree, E. F. (1957). Inositol in seminal plasma. Biochem. J. 66, 131.

HuGHES, D. E. (1951). A press for disrupting bacteria and other micro-organisms. Brit. $J$. exp. Path. 32, 97.

Kemp, P., Hübscher, G. \& Hawthorne, J. N. (1959). A liver phospholipase hydrolysing phosphoinositides. Biochim. biophys. Acta. 31, 585. 
Lebaron, F. N. \& Folch, J. (1956). The isolation from brain tissue of a trypsin-resistant protein fraction containing combined inositol, and its relation to neurokeratin. J. Neurochem. 1, 101.

Nojima, S. (1959). On the chemical structure of oligomannoinositides. J. Biochem. Tokyo, 46, 607.

Paulas, H. \& Kennedy, E. P. (1960). The enzymatic synthesis of inositol monophosphatide. J. biol. Chem. 235, 1303.

Posternak, Th., Reymond, D. \& Haerdi, W. (1955). Chromatographie sur papier de cyclitols et de cycloses. Helv. chim. Acta, 38, 191.

Ridgway, G. J. \& Douglas, H. C. (1958). Distribution of inositol in subcellular fractions of yeast cells. $J$. Bact. 75,85 .

Ryle, A. P., Sanger, F., Smith, L. F. \& Kitai, R. (1955). The disulphide bonds of insulin. Biochem. J. 60, 541.

Sмrт, R. H. (1951). A study of the role of inositol in the nutrition of Nematospora gossypii and Saccharomyces carlsbergensis. J. gen. Microbiol. 5, 772.

Trevelyan, W. E., Procter, D. P. \& Harrison, J. S. (1950). Detection of sugars on paper chromatograms. Nature, Lond. 166, 444.

Vilkas, E. \& LEDERER, E. (1956). Isolement d'un phosphatidyl-inosito-dimannoside a partir d'un phosphatide de mycobactéries. Bull. Soc. Chim. biol., Paris, 38, 111.

WILzBaCh, K. E. (1957). Tritium-labelling by exposure or organic compounds to tritium gas. J. Amer, chem. Soc. 79, 1013.

YARBRoUGH, H. F. \& Clark, F. M. (1957). Utilization of inositol, an essential metabolite for Schizosaccharomyces pombe. J. Bact. 73, 318. 